\title{
Designing an Electronic Training Course on Differential Equations and Its Application in the Framework of the Blended Learning Concept
}

\author{
Mukhanov S.A. ${ }^{1, *}$ Bogdanov M.R. ${ }^{1}$ Mukhanova A.A. ${ }^{2}$ \\ ${ }^{1}$ The Moscow Polytechnic University, Moscow, Russia \\ ${ }^{2}$ The Russian State Agrarian Correspondence University, Balashikha, Russia \\ *Corresponding author. Email: $\underline{\text { s_a mukhanov@mail.ru }}$
}

\begin{abstract}
The introduction of various information and distance technologies in the learning process continues to be relevant. Modern education has changed significantly under the influence of digital solutions that penetrate into it everywhere; previously impossible forms of organization of the educational process become popular. The article discusses the possibilities of using distance learning technologies using LMS Moodle as part of the implementation of the Blended Learning concept when teaching a course in higher mathematics, describes the use of the main stages and concepts of designing an electronic course. The principles of designing distance courses are formulated and justified: structuring the content of educational material and designing the logical structure of the course; planning of learning outcomes and development of diagnostic tools to achieve the planned learning outcomes; adaptation of the learning process to the personality of the learner, individualization, and differentiation of learning. Various methodologies for improving the quality of education are considered, such as problem statement and solution (PP\&S), virtual learning environment (VLE), Advanced Computing Environment (ACE) and automated assessment system (AAS).

Keywords: Blended Learning, distance learning, e-learning resources, Moodle
\end{abstract}

\section{INTRODUCTION}

The Federal Law "On Education in the Russian Federation" dated December 29, 2012, No. 273-FZ [1] introduces the concepts and possibilities of implementing a network form of educational programs (Article 15) and educational programs using e-learning and distance learning technologies (Article 16). In turn, one of the directions of the development of information and communication technologies in the long term is, including "the expansion of the use of information and telecommunication technologies for the development of new forms and methods of training, including distance education and media education." [2]

Traditional classroom education no longer meets the modern requirements for the educational process. The development of modern information technologies did not leave aside the education system. Distance learning using the means of new information technologies is greatly developed, but this form of training, in our opinion, can be effective, at least in the near future, only for highly motivated students, in particular, as a form of obtaining a second higher education or advanced training.

Nevertheless, the use of new forms and teaching methods in combination with the traditional classroom teaching form can significantly increase the effectiveness of the educational process. Thus, we come to the so-called mixed form of education.

The very concept of a mixed form of education emerged in the middle of the last century. So, for example, since 1964 Massey University (New Zealand) has been offering various training options, including a mixed system. [3] In 1999, the term "blended learning" was introduced by the American Interactive Learning Center, which developed software for online learning.

Foreign scholars give different definitions of blended learning, for example, as "a combination of technology and traditional classroom instruction based on a flexible approach to learning, which takes into account the benefits of training and monitoring tasks in the network, but also uses other methods that can improve student outcomes and save on costs learning" [4] or as" a combination of personal communication learning $(\mathrm{F} 2 \mathrm{~F})$ and programmed learning (CAL) in a single educational space". [5]

The blended learning model provides students with new opportunities for studying disciplines, since you can not only view the necessary material online at any time, but also take tests, test your knowledge on a particular topic or subject as a whole, and familiarize yourself with additional sources that exactly correspond to the ones you passed topics. [3, p. 56] 
According to J. R. Young, the combination of distance and full-time education is the only greatest and not yet a fully conscious trend in the development of modern education. [6] In 2003, the American Society for Learning and Development identified blended learning as one of the 10 key technologies associated with the transition to a knowledge economy. [7]

Blended learning allows you to effectively implement such modern requirements for the educational process as individualization, differentiation and, of course, personalization of training without losing the positive features inherent in the traditional model of learning.

As you know, individualization involves the study of the same material by students, but taking into account their individual knowledge and capabilities, a variation in the pace of studying educational material is possible. Differentiation refers to the construction of the learning process itself, adapted to the learning preferences of different students. Here, methods and approaches to learning are changing, different instructions are offered for different groups of students. Personalization involves adapting to the specific interests of different students. In an environment that is fully personalized, the goals, content, as well as the methods and pace of learning can vary (therefore, personalization encompasses differentiation and individualization). [8]

We offer using the LMS Moodle platform for blended learning design purposes. Despite the fact that this system is a platform for organizing distance learning, it has been used for a long time as a tool to support conducting classroom studies in a blended learning model $[9,10,11$, 12 , etc.].

Placing training material on LMS Moodle allows students to independently choose the pace and sequence of studying the material, if necessary, there is the possibility of returning to the previously studied material. Extensive communication opportunities in the student-teacher system also contribute to the individualization of the learning process. At the same time, despite the fact that all the necessary educational content is in the system, conducting traditional classes and allows you to implement the concept of Blended Learning.

As practice shows, the following blended learning models can be implemented in higher education:

For full-time education:

- Face-to-Face Driver is aimed at the translation of training material from teacher to students in full-time classes. Resources posted in the Moodle LMS are used only to consolidate knowledge;

- Self-blend is aimed for standard (full-time) study of educational material. Resources and courses hosted with LMS are used if they are of increased interest;

- Online Lab is aimed for students that use virtual laboratories, including in the Wolfram CDF format in which they set up experiments and solve educational cognitive problems under the guidance of a teacher in classroom classes in computer classes.

For partially full-time education:

- Rotation model is an alternation of full-time and online learning: involves the initial independent development of the material in the LMS, followed by fixing under the guidance of a teacher in full-time, and vice versa.

For distance learning:

- Online Driver: students learn material remotely in the LMS using all its resources. If necessary, in-person consultations with the teacher are organized.

- Flex model: priority is given to mastering the program courses through the LMS. The teacher in this model is assigned, rather, the role of coordinator. The coordinator needs to monitor topics that are difficult to understand and master, so that later, in person, they can be discussed in a group or individually.

Unfortunately, the balance between e-learning and face-toface learning is often not so easily achieved [13, 14]. Researchers pay considerable attention to improving the quality of education using the Blended Learning system $[15,16]$.

The development of research and analytical skills among students, however, requires a more systematic approach.

\section{RESEARCH METHODOLOGY}

In the course of the study, a systematic analysis of scientific and special methodological literature was conducted, devoted to the issues of the effectiveness of different models of distance and blended learning, the design of distance learning courses and innovations in teaching a mathematics course in higher education, the construction and organization of a blended learning model. In order to improve the quality of mathematical education, according to the results of the analysis of the literature, it is proposed to use the following methodologies:

- Problem statement and solution (PP\&S): a problematic situation is given in which new technologies are used to find a solution [17]

- $\quad$ Using the virtual learning environment (VLE): modern distance learning systems offer many tools for organizing both interactions in the student-teacher system and in the student-student system, which facilitate cooperation and the exchange of ideas in solving specific learning problems [18]. Also, modern distance learning can not do without various kinds of virtual laboratories that can be integrated into the course to establish a full-fledged virtual learning environment. 
- Using Advanced Computing Environment (ACE): the use of modern computer mathematics systems allows students to focus not on the technical aspects of the solution, such as computing, but on the formulation of a mathematical model of the process under study. [19]

- Using the Automated Assessment System (AAS): advanced student testing systems in modern LMS, for example, such as various types of questions, including those computed or generated by a specific algorithm. Together with developed systems for analyzing student test results, they allow unloading the teacher and optimizing the teacher's control function in the educational process. [20]

Practical research methods include: introducing the developed electronic courses and testing them both with part-time students (mainly as distance learning courses), and with full-time students in the framework of the Blended Learning concept, i.e. combining classroom learning with learning with LMS Moodle; interrogation and questioning of students of the course; comparative analysis of academic performance of the experimental and control groups, analysis of the results of the control of residual knowledge.

\section{BACKGROUND}

\subsection{Development of the logical structure of the course}

As the basis for designing the course, we have chosen the technology for designing the educational process of academician V.M. Monakhov [21]. We started developing the training course at LMS by designing its logical structure. As a basis for designing, we will choose a micro-goal: a brief record of basic knowledge and skills that students should master. In addition to a clear and concise statement, the goal of the training should be diagnosed, that is, the mechanism for the simple establishment of the fact that students achieve this microgoal is obvious.

The construction of the logical structure of the course in the form of links of micro-goals also allows us to present possible trajectories of its study and the possibility of optimizing the sequence of presentation. For example, in the Moodle environment, you can adjust the visibility of elements depending on the fulfillment of certain conditions, for example, completing the study of a certain previous element, which allows students to automatically build individual educational paths that do not violate the internal logic of the course.

For the section of the course "Differential Equations" we have designed the following micro-goals:

- G1 Know the concept of a differential equation, its general and particular solutions,
- G2 Know the geometric interpretation of a first order differential equation,

- G3 Be able to solve differential equations with separated and separable variables,

- G4 Be able to solve homogeneous firstorder differential equations,

- G5 Be able to solve differential equations that lead to homogeneous,

- G6 To be able to solve linear differential equations of the first order by the Lagrange method (by varying an arbitrary constant) and Bernoulli,

- G7 Be able to solve the Bernoulli equation,

- G8 Be able to solve the equation in full differentials

- G9 Know the terminology of the section "Differential equations not resolved with respect to the derivative", be able to solve the Lagrange and Claireaux equations

- $\quad$ and others, total 18 items.

As a result, the following logical structure of the course was obtained:

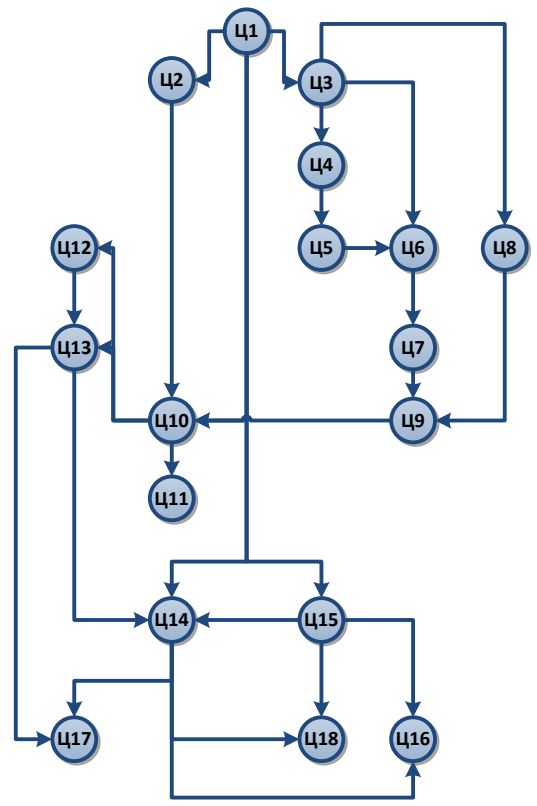

Figure 1 The logical structure of the course

\subsection{Course Content Development}

After building the micro-goals system, it is necessary to design a diagnosis of their achievement. Tests for LMS were developed in accordance with the AAS methodology. It was rather difficult to design the contents of the test using differential equations, because the format of the test in closed form does not allow you to check the progress of the solution.

As a result, this form of verification was implemented only with the response form that students could enter in the response input line. 
In addition to actually designing the content of the test, it is also necessary to pay considerable attention to obtaining objective characteristics that allow us to evaluate the quality of the tests and their components, test questions. One of the undoubted advantages of tests and, first of all, in the computer version is that they can be used repeatedly. This makes it possible to use statistical methods in assessing the quality of the test in calculating a number of characteristics that are used both for their assessment as a whole and for the evaluation of individual test questions. The statistics collection system is based on the Rash Measurement metric system, which allows talking about the quality of pedagogical measurements. [22]

To analyze the test results in the framework of Rash Measurement, the initial data are needed in the form of a matrix, which is usually binary.

Another great opportunity provided by Moodle is that, according to the test results, the system automatically generates a very informative report that allows you to analyze statistical indicators obtained by the test, including using Rash Measurement, which provides a convenient tool for designing tests.

In addition to tests, the course included sets of typical tasks and situations from future professional activities in which students had to apply their knowledge (in accordance with the PP \& S methodology).

Problem situations were supplemented by virtual laboratories (according to ACE methodology). There are ready-made virtual laboratories written in Java Script that are easily integrated into distance learning courses. Another very effective design tool for EER may be the CDF format developed by Wolfram Research. Files of this type are a knowledge container with a computing engine. A key feature of this file format is the ability to perform dynamic mathematical calculations in real time using a large number of features of the popular computer mathematics system Wolfram Mathematica, its built-in algorithms and the processing capabilities of highly specialized data. All this allows you to realize amazing opportunities for interactive work with content in real time. Often, virtual labs are licensed under a Creative Commons license to help legally share works and foster collaboration between authors.

\subsection{Project implementation}

When implementing the project with full-time students, the Online Lab model was used, when students were asked to perform tasks on virtual simulators as part of the PP\&S methodology. Online-driver models were mainly used with part-time students: students master the material remotely in the LMS using all its resources. If necessary, in-person consultations are organized with the teacher and the Flex model when priority was given to mastering the program courses through LMS. The teacher in this model is assigned, rather, the role of coordinator. The coordinator needs to monitor topics that are difficult to understand and master, so that later, in person, they can be discussed in a group or individually.
In percentage terms, the number of marks "good" and "excellent" for students connected to the electronic course in the exam turned out to be $15 \%$ higher, and the marks "unsatisfactory" $10 \%$ lower than among other students of the same stream.

The results of the control of residual knowledge conducted after six months corresponded to the results of the exam, reflecting a fairly high level of knowledge of the material.

\section{CONCLUSION \& DISCUSSION}

Currently, the dynamics of the design and implementation of blended learning in higher education is positive, which naturally reflects the general trend of digitalization of society.

Modern LMS can qualitatively increase the level of teaching higher mathematics. The availability of tools for the implementation of modern methodologies for improving the quality of mathematical education, such as PP\&S, VLE, ACE, and AAS allows to build an effective process for studying higher mathematics courses.

Meanwhile, "focusing on electronic learning formats poses risks of cognitive deformation and narrowing the range of perception of information. A combination of traditional and e-learning, blended learning, can help reduce these risks". [23]

Thus, the blended learning model for the course of differential equations is justified, however, it requires careful design of the course at all its stages.

In general, a mixed approach to learning gives more interactivity and stimulates active learning, motivates students to educational and cognitive activities, allows you to build self-learning skills.

\section{REFERENCES}

[1] Sobranie zakonodatel'stva RF, 31.12.2012, № 53 (ch. 1), st. 7598 .

[2] Rasporyazhenie Pravitel'stva RF ot 17.11.2008 N 1662-r «O Koncepcii dolgosrochnogo social'noekonomicheskogo razvitiya Rossijskoj Federacii na period do 2020 goda».

[3] Hyria, N. P. (2015) Effektivnost' primeneniya modeli smeshannogo obucheniya v kurse teorii funkcij kompleksnogo peremennogo. Information Technologies and Learning Tools, 46.

[4] E. Banados A blended-learning pedagogical model for teaching and learning EFL successfully through an online interactive multimedia environment. CALICO Journal. 2006. № 23 (3). P. 533-550.

[5] Bonk C. . The handbook of blended learning environments: Global perspectives, local designs / C. J. 
underachievement in higher education: An experience in teaching computer sciences," IEEE Transactions on Education, vol. 54, no. 3, pp. 471-478, 2011.

[17] Brancaccio, A., Demartini, C., Marchisio, M., Palumbo, C., Pardini, C., Patrucco, A., \& Zich, R. (2015a). Problem Posing and Solving: Strategic Italian Key Action to Enhance Teaching and Learning of Mathematics and Informatics in High School. Proceedings of COMPSAC Symposium on Computer Education and Learning Technologies (CELT).

[18] Lave, J. (1991). Situating Learning in Communities of Practice. In L. B. Resnick, J. M. Levine, \& S. D. Teasley, Perspectives on socially shared cognition (63-82). American Psychological Association.

[19] Palumbo, C., \& Zich, R. (2012). Matematica ed informatica: costruire le basi di una nuova didattica. Bricks, 2(4), 10-19.

[20] Barana, A., \& Marchisio, M. (2016). Ten good reasons to adopt an automated formative assessment model for learning and teaching Mathematics and scientific disciplines. Procedia - Social and Behavioral Sciences. 228, 608-613. Valencia: Elsevier.

[21] Monahov V.M. Vvedenie v teoriyu pedagogicheskih tekhnologij: Monografiya. Volgograd, 2006. $-318 \mathrm{~s}$.

[22] Avanesov V.S. Primenenie testovyh form v Rasch Measurement. - Pedagogicheskie izmereniya, 2005, N 4. - S. 3-20.

[23] Bataeva E.V. COGNITIVE AND METACOGNITIVE SKILLS OF STUDENTS IN THE CONTEXT OF SMART-EDUCATION. The Education and science journal. 2019;21(4):36-59. (In Russ.) https://doi.org/10.17853/1994-5639-2019-4-36-59
[14] R. Shen, M. Wang, W. Gao, D. Novak, and L. Tang, "Mobile learning in a large blended computer science classroom: System function, pedagogies, and their impact on learning," IEEE Transactions on Education, vol. 52, no. 4, pp. 538-546, 2009.

[15] F. Martinez-Rodrigo, L. S. Herrero-De Lucas, S. de Pablo, and A. B. Rey-Boue, "Using PBL to improve educational outcomes and student satisfaction in the teaching of DC/DC and DC/AC converters," IEEE Transactions on Education, 2017.

[16] F. Alonso, D. Manrique, L. Mart'inez, and J. M. Virnes, "How blended learning reduces 